\title{
Optimisation of Artificial Lifts Using Prosper Nodal Analysis for BARBRA-1 Well in Niger Delta
}

\author{
Tega Odjugo ${ }^{1}$, Yahaya Baba $^{1 *}$, Aliyu Aliyu ${ }^{2}$, Ndubuisi Okereke $^{3}$, Lekan Oloyede $^{4}$, Olabisi Onifade $^{5}$ \\ ${ }^{1}$ Department of Chemical and Petroleum Engineering, Afe Babalola University, Ado-Ekiti, Nigeria \\ ${ }^{2}$ Department of Engineering \& Technology, University of Huddersfield, United Kingdom \\ ${ }^{3}$ Department of Petroleum Engineering, Federal University of Technology, Owerri, Nigeria \\ ${ }^{4}$ Department of Mechanical and Mechatronics Engineering, Afe Babalola University, Ado-Ekiti, Nigeria \\ ${ }^{5}$ Department of Electrical and Computer Engineering, Afe Babalola University, Ado-Ekiti, Nigeria
}

\begin{abstract}
Hydrocarbon exploration basically requires effective drilling and efficient overpowering of frictional and viscosity forces. Normally, frictional power losses occur in deep well systems and it is essential to analyse each component of any well system to determine where exactly pressure is lost, and this can be done using Nodal Analysis. In this study, nodal analysis has been carried out with the use of PROSPER, a software for well performance, design and optimisation. Artificial lifts can then be used to solve the problem of frictional power losses. To increase the production of Barbra 1 well in the Niger Delta and hence extend its functional life, we have applied nodal analysis. Modelling results for three artificial lift methods; continuous gas lift, intermittent gas lift and electrical submersible pump were found to be $1734.93 \mathrm{bbl} / \mathrm{day}, 451.50 \mathrm{bbl} / \mathrm{day}$ and $2869 \mathrm{bbl} /$ day respectively. The output from the well performance without artificial lift was 1370.99 bbl/day by applying Darcy's model. Meanwhile, the output from the well without artificial lift is $89.90 \mathrm{bbl} /$ day when aided with productivity index (PI) entry, the normal model for intermittent gas lift. Hence, from the comparative analysis of the results obtained from this study, it was deduced that when artificial lifts are employed, the well output increases significantly from 1370.99bbl/day to $2869 \mathrm{bbl} / \mathrm{day}$ (electrical submersible pump). This study concludes that wells such as Barbra 1 are good candidates for artificial lift, and this is evidenced by increasing productivity.
\end{abstract}

KEYWORDS: Production optimisation, nodal analysis, prosper simulator and barbra well.

[Received December 27, 2019, Revised April 11, 2020, Accepted June 29, 2020]

Print ISSN: 0189-9546 | Online ISSN: 2437-2110

\section{INTRODUCTION}

During hydrocarbon production, friction losses must be effectively overcome in order for the fluid to flow to the surface with the initial well bed pressure. The fluid travels from the reservoir through the piping system to the surface. A well output or production rate is its ability to deliver hydrocarbons to the atmospheric level and it can be affected by the performance of any of the units in the well piping system. Therefore, there is need to analyse each unit of the system using nodal analysis. Nodal analysis is a method of systematically assessing a well as a complete system with different components and analysing each component for the pressure loss at that point. It is important to construct a model of the well with reservoir production variables.

Pressure loss may be due to friction or viscosity of the fluid (more pressure is required to carry a viscous fluid). When nodal analysis has been carried out then there is need to solve the problem that caused the pressure loss at that component to optimize flow. Artificial lift is one of the major solutions in the industry for solving pressure losses and heavy fluids flow challenge. It can be applied to solve problems involving underor over-sized tubing or flow lines. These restrict and/or reduce production rate. One of the most common and most applicable lift systems is Gas lift system.
Gas lift is the method of injecting gas into the well bore fluid in order to aerate it and make it flow easily to the surface facility. This study is focussed on optimizing gas lift methods to increase its efficiency in solving pressure losses in the well using PROSPER to carry out nodal analysis in this project. PROSPER (Productions and systems performance analysis system) is a commercial software used in optimizing operating conditions existing well system and predicting the effects of future changes in various reservoir and production parameters.

Barbra 1 well has been drilled in the Niger Delta and has been identified to have a short life span without artificial lifting. The short life span of the well is attributed to the decrease in reservoir energy which results in a decline in production. In the oil and gas industry decline in production is a serious problem which can be caused by excessive pressure drops along the production system, bad management of wells, usage of oversized and undersized tubing. The components in a production system are interactive therefore when one of the components is changed there may be a change in the pressure drop behaviour of the other components.

A well deliverability as indicated by Amanat Chaudhry, 2003 and Belyadi et al., 2019 is the well's capability to deliver liquid and gas given the well reservoir's pressure. The two main parameters that determine a well deliverability are its inflow and outflow performance. The inflow performance 
directly determines the reservoir's deliverability while outflow performance accounts for the resistance of flow during production. The main reason why deliverability analysis is carried out is to determine the level of achievable fluid production rates from reservoirs given certain production string characteristics. This analysis is otherwise known as Nodal Analysis Clegg et al.,1993.

Nodal analysis has previously been applied for the quantification of the performance of systems composed of interrelating components. Examples include complex pipeline networks, centrifugal pump systems and electrical circuits. Application of nodal analysis to well-producing systems was first proposed by Gilbert, 1954. Tetoros, 2015 noted that the concept was further established (Mach et al., 1979). To carry out nodal analysis, a specific point within the system (i.e. the node) is selected and the system is subdivided in two component segments. The components upstream of the node encompass the inflow part and those downstream are the outflow components. The behaviour of each component in the system is then directly linked to pressure drop and flow rate. The fluid flow rate across the entire system is then calculated once the following requirements are met Vogel, 1968: node inflow equals node outflow such that only one pressure can subsist at a node. As an illustration, the numerous positions of the nodes are as given in Figure 1.

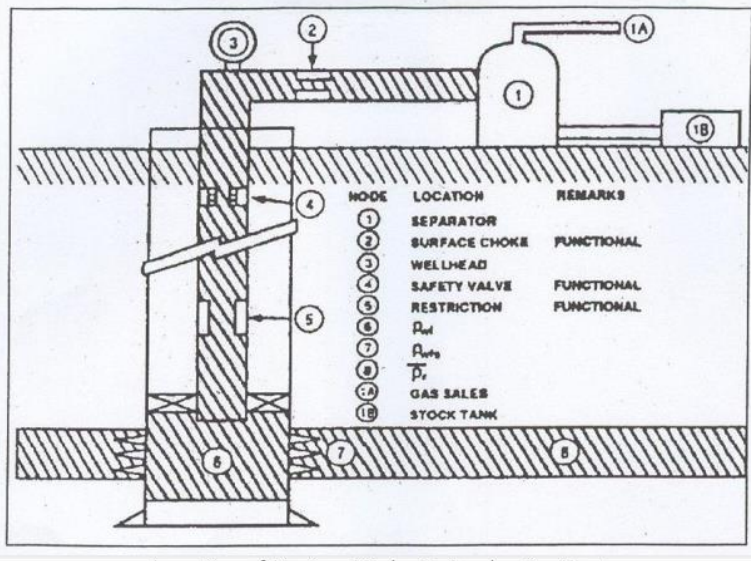

Location of Various Nodes in Production System

Figure 1: Location of Various Nodes in Production System Beggs, 1991

The pressures of both reservoir and separator or wellhead, are fixed. Since the node has a unique pressure, the following expressions can be used (Ibrahim, 2007)

$$
\begin{aligned}
& P_{\bar{r}}-\Delta p_{\text {upstream }}=P_{\text {node }} \\
& P_{\text {wh }}-\Delta p_{\text {downstream }}=P_{\text {node }}
\end{aligned}
$$

Where $P_{\bar{r}}$ : The average reservoir pressure (psi), $P_{w h}$ is the wellhead pressure (psi), $\Delta p_{\text {upstream }}$ is the pressure loss as a result of upstream components (psi), and $\Delta p_{\text {downstream }}$ is the pressure loss due to upstream components (psi). The aim of this paper is to analyse parameters that affect the production of Barbra 1 well by modelling systems that can optimize a continuous gas lift, intermittent gas lift and electrical submersible pump using PROSPER software to carry out nodal analysis. This was achieved through the following objectives: modelling the components of a well system separately and verifying each of the model subsystems by performance matching using prosper which will ensure accurate calculation, modelling the well in various scenarios so as to calculate the future performance of the wells and recommend the best scenario in which the well would be fully optimised for current operating conditions.

A summary of the existing works carried out on gas lift are given. Bieker et al. (2007) reported a technological survey on real time production optimisation of oil and gas production systems. Optimisation of the system was done using collected data, processing, and model updating. Production and strategic planning were achieved as result. Litvak \& Angert (2009) reported work on the application of field development optimisation to large oil fields. A robust optimisation procedure based on Genetic Algorithm which is a global optimisation method was employed together with mixed integer optimisation. Stephenson et al. (2010) did a case study on utilising real-time fault detection of gas lift systems using intelligent algorithms and was a novel method for nonstop monitoring of wells producing by way of continuous gas lift. Furthermore, the applying such a system in a developed onshore gas lift fields in the western parts of the United States of American and their findings were extensively discussed.

Ageh et al. (2010) carried out an integrated method of production modelling for optimising field development planning as well as management. The Petroleum experts (PETEX) modelling tool was used for evaluating the Bonga North deep-water subsea tie-back development, the software allowed the incorporation of flow assurance into subsurface deliverability and this also includes considering the effect of both existing and envisaged topside constraints.

Tetoros, 2015 worked on the designing a continuous gas lift system to initiate production in a dead well. The main work was to design a gas lift system which assisted production during current operating conditions and future forecasting. Unlike the other works discussed above, the purpose of this paper is to perform an optimisation on continuous and intermittent gas lift. An electrical submersible pump for an oil well was simulated using the flow simulator PROSPER to comprehensively carry out nodal analysis.

\section{NUMERICAL SIMULATION}

This study was carried out using PROSPER software developed for the purpose well performance design and optimisation. PROSPER enables the modelling of most types of well completions and artificial lift techniques. It permits the construction of different well models and has the ability to access all variables like well configuration, fluid PVT characteristics, multiphase Vertical Lift Performance (VLP) correlations and various Inflow Performance Relationship (IPR) models. The model can be tuned by matching real field production data aimed towards increase the accuracy of different model scenarios. The major application of PROSPER 
is the calculation of VLP using multiphase flow correlations with the evaluation of the variables of VLP. Sensitivity analysis can be easily done on forecasted changes to parameters that influence both IPR and VLP. An illustration of IPR input data is given in Figure 2 below. These include specification of the PVT method for which the Black Oil model. The fluid was assumed to display Newtonian behaviour and effective viscosity was calculated using the correlation of Beggs Dales, 1991. For the intermittent gas lift method, the electrical submersible pump was used.

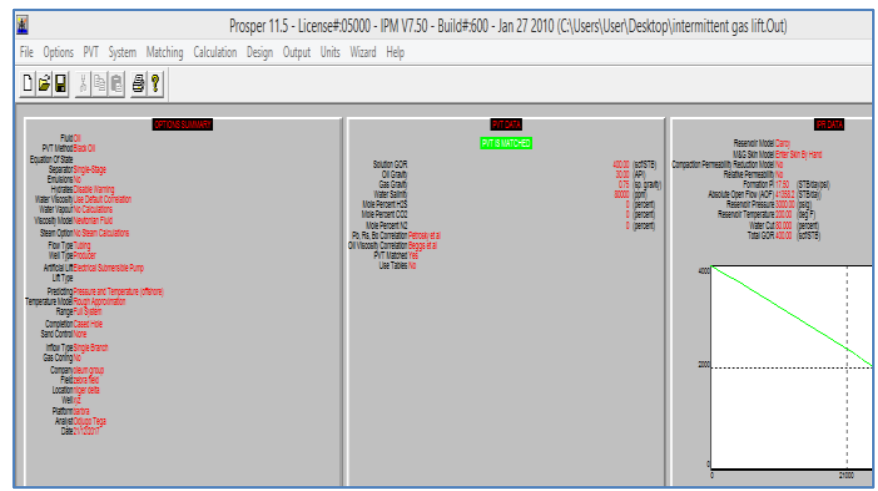

Figure 2: Data input interface.

\section{A. IPR and Equipment Data}

The IPR curve can be made after the PVT data has been adequately matched. There are many models for making the IPR. For this well, the Darcy model was selected due to its simplicity and ease of convergence. The Productivity index inserted is used in the calculation of IPR. Furthermore, the liquid rates are the same as IPR rates. The IPR input as shown in Figure 2 is based on the simulation made by the FINUS reservoir department using Eclipse. To enable the calculation of pressure and temperature profiles along the well, there is need for temperature (geothermal gradient and average heat capacity), completion (down-hole equipment) and survey data. For Electrical submersible pump or Gas lift (continuous or intermittent) to be implemented, a full work-over is necessary. The ESP's is a part of the tubing and the well contains no side pockets such that gas lift valves are connected by wireline. PROSPER simulations therefore uses the well current completion.

\section{B. Building Gas Lift Models}

In the modelling of a continuous gas lift model, a number of parameters are required. The artificial lift in the system summary is first changed to gas lift (continuous) the data was inputted. The modelling of the intermittent gas lift model is similar to that of the continuous lift gas model only that the artificial lift method in the system summary for this case is changed to gas lift (intermittent) and the appropriate intermittent gas lift data are inputted. The modelling of an electrical submersible pump is slightly different from that of the continuous and intermittent gas lift models. The first step is to change the artificial lift method in the system summary to electrical submersible pump. The design of the pump is done in two stages. Firstly, the ESP scenario is selected from the design menu then the applicable pump is selected from the dropdown list. An alternative option is to key in the pump data directly once a decision has been made on the choice of pump and motor.

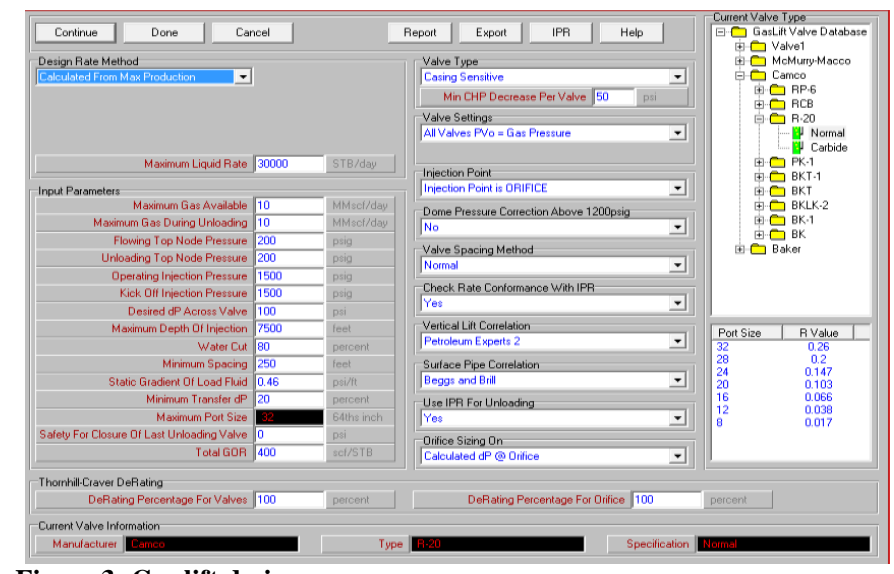

Figure 3: Gas lift design menu.

\section{RESULTS AND DISCUSSION}

Once models for different scenarios have been built, the IPR curve and VLP curve for each case is plotted to determine the production point. This point is the intersection between the VLP and IPR curves.

\section{A. Base Model Results}

The input parameters for the base case model gives the production profile without artificial lift for the Barbra well with an oil production rate of $1370.9 \mathrm{stb} / \mathrm{d}$. Production is however low given the volumetric analysis of the reservoir. Water cut is the major cause of the reduction in oil production as more energy is lost in transporting the reservoir fluid to the surface. Production of the well would last for a short period of time and there would be no production point again. Figure 4 shows the well production point which is the crossing between the VLP and IPR curves.

Figure 5 shows the well bore pressure in psig plotted as a function of liquid rate in stb/day. The plot shows comparison between result obtained for this study and those of Tetoros, 2015 field data. The result exhibits a similar trend at low production rates. The points however deviated at a liquid rate of $14646 \mathrm{stb} /$ day and at a pressure of $3076 \mathrm{psig}$ for Tetoros's data. With the deviation occurring at a liquid rate of 11548 stb/day and at a pressure of $3076 \mathrm{psig}$, this shows that the pressure of Tetoros's data declines at a slower rate (Figure 5). The same pressure for the well's data produces a lower liquid rate than for the same pressure at the Tetoros's data. The reason for this difference in liquid rate might be due to varying fluid properties.

\section{B. Continuous Gas Lift Models Results}

The result outputted based on the gas lift design is presented in Error! Reference source not found.. The result shows that well will be significantly increased in the production of oil from the injection of gas. Three unloading valves would be required. This is as a result the combination 
of load fluid density, depth setting of the operating valve and the injection pressure of gas lift.

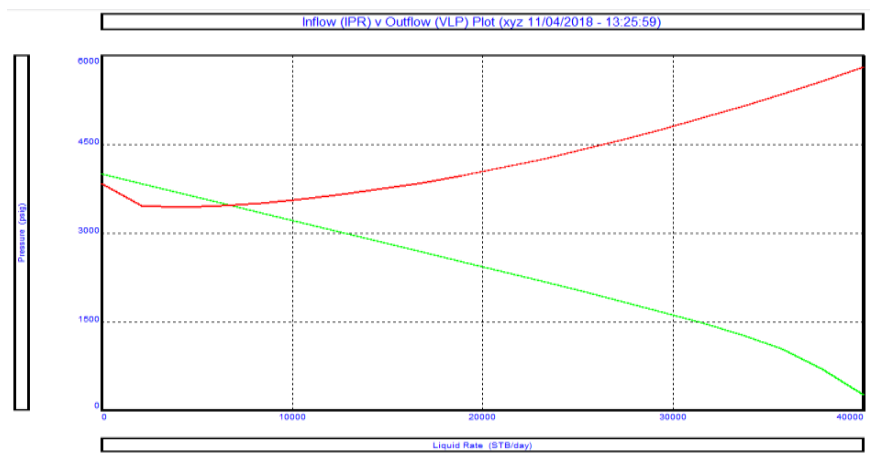

Figure 4: Barbra 1 well production point (this is the intersection between the IPR and VLP curves).

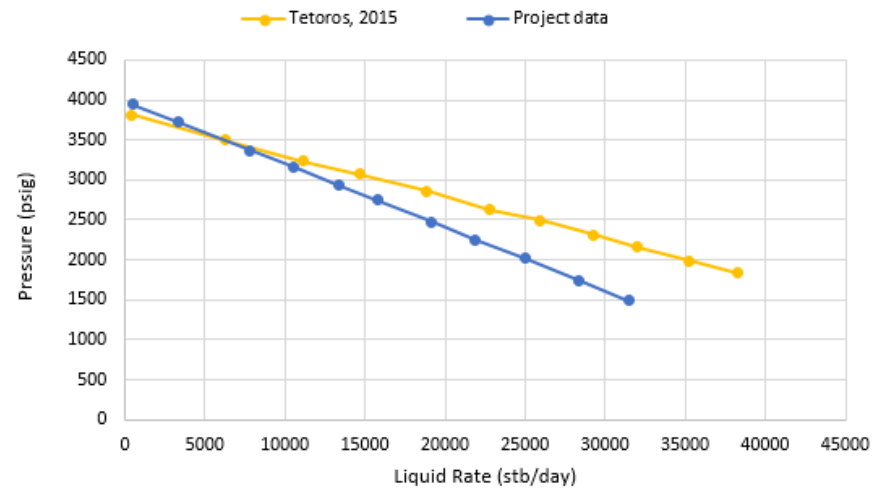

Figure 5: Comparison between present study and the work of Tetoros (2015).

Table 1: Results from continuous gas lift design.

\begin{tabular}{lc}
\hline Result & Barbra 1 well \\
\hline Depth of unloading valve 1, feet MD & 2980.24 \\
Depth of unloading valve 2, feet MD & 4706.51 \\
Depth of unloading valve 3, feet MD & 5544.33 \\
Unloading valve port size, 64ths inch & 14.00 \\
Depth of operating valve, feet MD & 5804.54 \\
Injection pressure, psig & 1321.08 \\
Injected gas rate, MMscf/day & 5.48 \\
Operating valve port size, 64ths inch & 14.00 \\
Oil rate with continuous gas lift, stb/day & 1734.93 \\
Oil rate without gas lift, stb/day & 1370.90 \\
\hline
\end{tabular}

Table 2: Injection analysis of the Barbra 1 well.

\begin{tabular}{cc}
\hline Injection depth (feet, MD) & Oil production (stb/day) \\
\hline 3280.84 & 960.00 \\
4921.26 & 1465.80 \\
6561.68 & 1857.80 \\
7545.93 & 2021.60 \\
\hline
\end{tabular}

Considering a well without depth constraints that is moved to a $900-\mathrm{kg} / \mathrm{m}^{3}$ fluid instead of seawater at the start of injection, the operating valve would be set deeper and there would be an increase in production. In order to determine injection depth effects on the production, a sensitivity analysis was done. Error! Reference source not found. shows the results of the sensitivity study in terms of oil production rate at different tubing depths. From the table, it can be seen that the production rate is approximately proportional to injection depth with a near linear relationship. Figure 4 gives the tendency of several
VLP curves as a function of injection depth. From the plot, it is seen that a higher operating valve setting depth results in increased production.

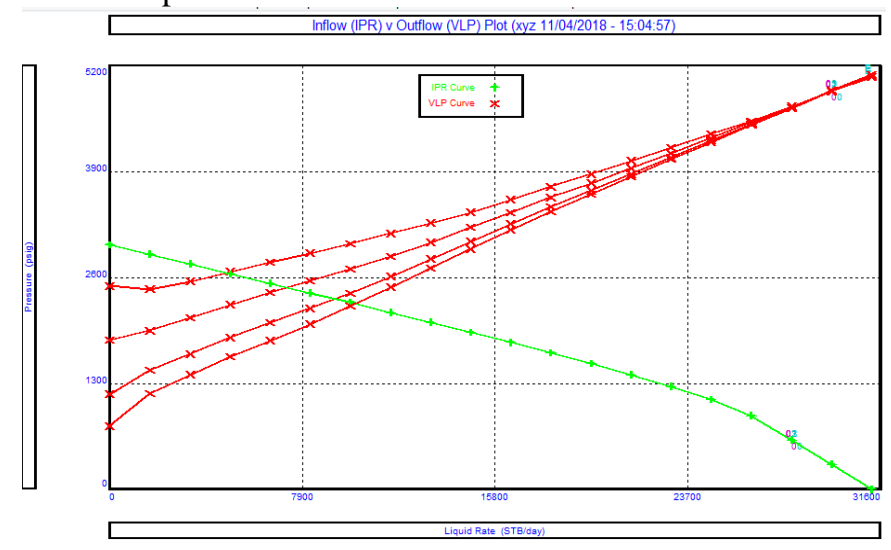

Figure 6: Injection depth analysis on Barbra 1 well.

\section{Intermittent Gas Lift Model Results}

Following the design of intermittent gas lift model, the results obtained are presented in Table 1 . The oil production rate is seen to be different from that of the continuous gas lift because the reservoir model applied for the intermittent gas lift in the IPR data is PI entry. This is because when the Darcy model is used for this case, a solution point cannot be obtained as can be seen in Figure 5. From the results it can be observed that there are only two unloading valves needed for the intermittent gas lift design. The increase in production is however high when the PI model is considered. The oil production increases from a rate of $89.9 \mathrm{stb} /$ day to 451.5 stb/day as seen in Figure 8. The injection of the gas intermittently causes spikes in the VLP curve because of the unsteady injection of gas.

\section{Result of Electrical Submersible Pump Model}

Coefficients for horsepower and head received by Centrilift is inputted into the PROSPER software's database. With the pump curves' coefficients to enable simulation for any well condition. From Figure 8 showing maximum and minimum operating range, best efficiency line and operating ranges denoted in red, blue and green colours respectively. It can be seen that the least operating range of $60 \mathrm{~Hz}$, is $9486 \mathrm{bbl} /$ day and the top limit is $14484 \mathrm{bbl} /$ day.

Table 1: Results of Intermittent gas lift design.

\begin{tabular}{ll}
\hline Result & Barbra 1 Well \\
\hline Depth of unloading valve 1, feet MD & 3121.09 \\
Depth of unloading valve 2, feet MD & 5111.56 \\
Depth of operating valve, feet MD & 6699.45 \\
Injection Pressure of unloading valve 1, psig & 1485.70 \\
Injection Pressure of unloading valve 2, psig & 1604.13 \\
Injection Pressure of operating valve, psig & 1698.61 \\
Closing Pressure of unloading valve 1, psig & 1685.70 \\
Closing Pressure of unloading valve 2, psig & 1804.13 \\
Closing Pressure of operating valve, psig & 1898.61 \\
Gas injection rate, Mscf/day & 49.14 \\
Oil rate with Intermittent gas lift, stb/day & 451.50 \\
\hline
\end{tabular}




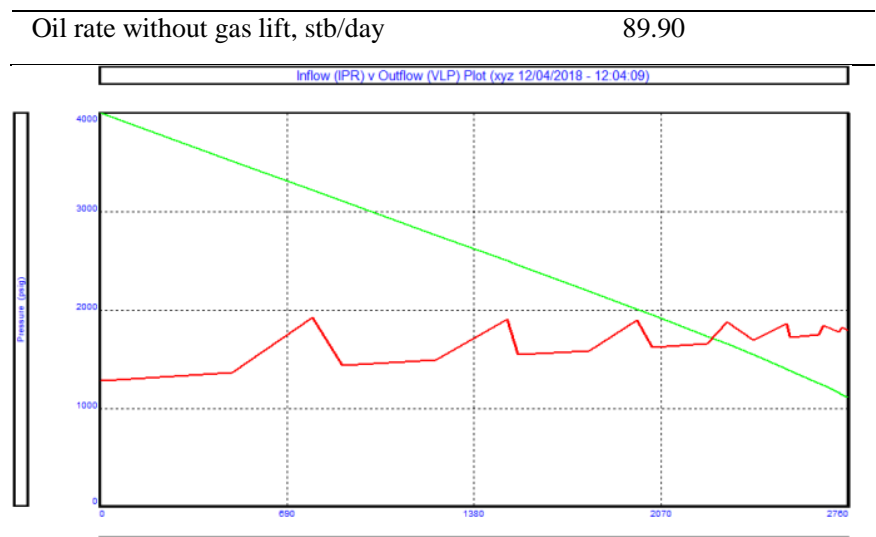

Figure 7: Solution intersection point for Darcy PI model denoted in red and VLP outflow line denoted in green.

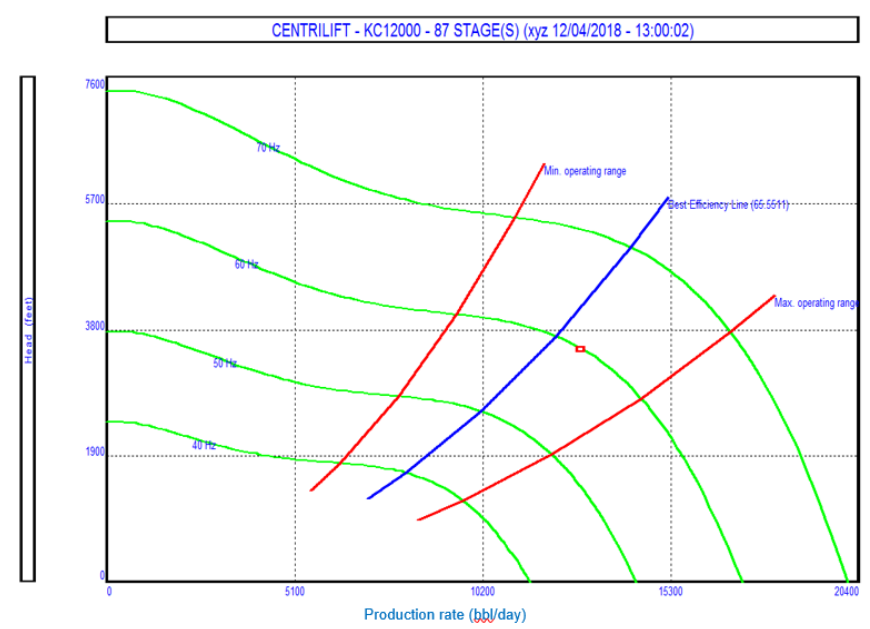

Figure 8: Pump curves for the centrilift.

Table 4: Electrical submersible pump model result.

\begin{tabular}{ll}
\hline Result & Barbra 1 Well \\
\hline Oil rate with ESP, bbl/day & 2869.00 \\
Total liquid rate ESP, bbl/day & 14344.90 \\
Oil rate without artificial lift, bbl/day & 1370.90 \\
Oil rate with continuous gas lift, bbl/day & 1734.93 \\
\hline
\end{tabular}

The ideal operating point is obtained at or near the best efficiency line. At this point, the efficiency curve for the pump is greatest. Given the conditions of the well and ESP data, the production in the ESP is then calculated by PROSPER and the results are shown in Error! Reference source not found.

The well shows a significant increase in production for the ESP case when compared with the base case and continuous gas lift case. The total liquid rate is almost close to the maximum operating range which means there is little capacity to handle more fluid. Similarly, from Figure 9 which shows a plot production rate versus pressure, the green curve is the pump discharge pressure, which is the inlet pressure of the pump adjusted for losses additional pump losses, while the red curve is the VLP from wellhead to pump discharge. The intersection of pump discharge pressure and the VLP gives the solution rate.

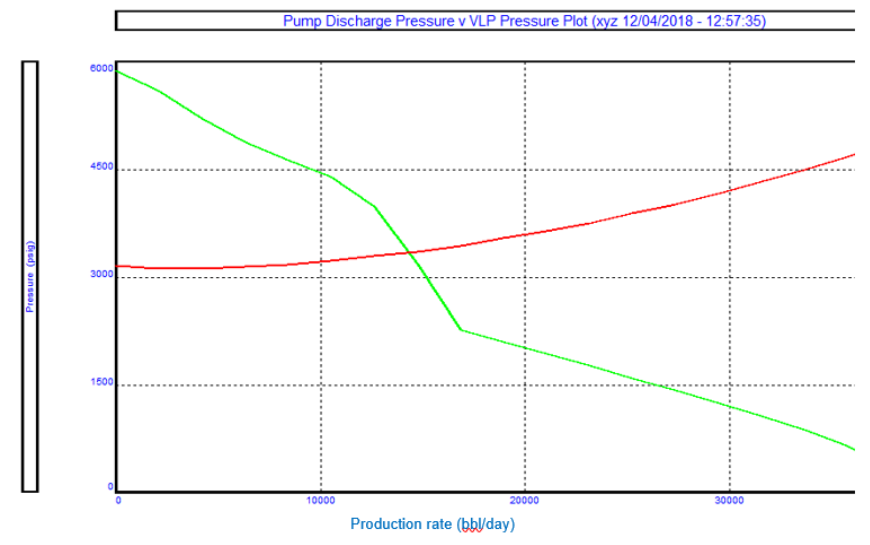

Figure 9: Well ESP system.

\section{CONCLUSION}

This study was carried out to design model systems in the flow simulator PROSPER to analyse a production well: Barbra 1 using nodal analysis to solve the problem of under-utilisation of continuous gas lift, intermittent gas lift. An electrical submersible pumps characteristic in increasing the production rate of the well was assessed. We created a mathematical model that consists of several sub-models, for the prediction of attainable fluid production rates under different operating conditions. Modelling parameters such as the IPR curve, PVT data, downhole equipment and temperature profile along the well was done for both the base case model, the continuous gas lift model, the intermittent gas lift model and the electrical submersible pump.

The best artificial lift to be used from the modelling results was shown to be the Electrical submersible pump. This is because of its high production rate when applied to the well conditions, however, there are power costs associated with its operation. The continuous gas lift method is also applicable, but the intermittent gas lift would not improve the conditions of the well significantly. We note that, while the work carried out here produced successful results, in actual fact, production optimisation is very complex, and every well cannot be optimised individually. In cases where more wells are considered, optimisation software such as GAMS and GAP from PETEX are necessary for application in order to achieve full field optimisation and maximise income from well operations.

\section{REFERENCES}

Ageh, E. A.; A. Adegoke and O. J. Uzoh. (2010). Using Integrated Production Modeling IPM as an Optimisation Tool for Field Development Planning and Management, pp 1-11, In 34th Annual SPE International Conference and Exhibition. Calabar, Nigeria: SPE.

Ahmed, T. (2014). Reservoir Engineering Handbook 2nd Edition, Houston, Texas: Gulf Professional Publishing. https://doi.org/10.1007/s007690000247

Beggs, H. Dales. (1991). Production Optimisation Using Nodal, 2nd Edition, OGCI and Petroskills Publications Tulsa, Oklahoma, USA. 
Bieker, H. P.; O. Slupphaug, and T. A. Johansen. (2007). Real-Time Production Optimisation of Oil and Gas Production Systems : A Technology Survey. In SPE Intelligent Energy Conference and Exhibition, Amsterdam, 11-13.

Chaudhry, A. (2003). Gas Well Testing Handbook Copyright (C) Elsevier Inc. ISBN 978-0-7506-7705-9, https:doi.org/10.1016/B978-0-7506-7705-9.X5000-X

Clegg, J. D.; N. W. Heln and S. M. Bucaram. (1993). Recommendations and Comparisons for Selecting ArtificialLift Methods. Journal of Petroleum Technology, 45(12): 11281166.

Gilbert, W. E. (1954). Flowing and Gas-lift Well Performance. In Sprlng meeting of the Pacific Coast District, Divlsion of Production, American Petroleum Institute, New York, USA, 1-32.

Guo B., L. W. (2007). Petroleum Production Engineering. A Computer-Assisted Approach (ISBN: 0750). Elsevier Science \& Technology Books.

Belyadi, H.; E. Fathi and F. Belyadi (2019) Hydraulic Fracturing in Unconventional Reservoirs: Theories, Operations, and Economic Analysis, 2nd Edition, Elsevier Publishing Inc. ISBN 978-0-12-817665-8.

Ibrahim, A. T. M. (2007). Optimisation of Gas Lift System in Varg Field. Master's Thesis, Universiteteti Stavanger, Norway.
Litvak, M. and Angert, P. (2009). Field Development Optimisation Applied to Giant Oil Fields. In SPE Reservoir Simulation Symposium, Texas, USA, 2-4.

Mach J.M.; E.A. Proano and K.E. Brown. (1979) A nodal approach for applying systems analysis to the flowing and artificial oil and gas well, paper SPE 8025: 1082-1096.

Petex - Petroleum Experts. (2010). PROSPER. Retrieved December 22, 2017, from http://www.petex.com/products/?ssi=3

Petrowiki. (2015). Artificial lift. Retrieved December 27, 2017, from http://petrowiki.org/Artificial_lift

Stephenson, G.; R. Molotkov; N. D. Guzman and L. Lafferty. (2010). Real-Time Diagnostics of Gas Lift Systems Using Intelligent Agents : A Case Study. SPE Production \& Operations, (February), 111-123.

Tetoros, I. E. (2015). Design of a continuous gas lift system to initiate production in a dead well. Technical University Of Crete, Greece.

Vogel, J. V. (1968). Inflow Performance Relationships for Solution-Gas Drive Wells. Journal of Petroleum Technology, 20(1), 83-92. https://doi.org/10.2118/1476-PA 